\title{
The Optimization of Microgrids Operation through a Heuristic Energy Management Algorithm
}

\author{
Bogdan Tomoiagăa ${ }^{1, a}$, Mircea Chindriş, ${ }^{1, b}$, Andreas Sumper ${ }^{2,3, c}$ \\ and Mousa Marzband ${ }^{3, d}$
} ${ }^{1}$ Power Systems \& Management Department, Technical University of Cluj-Napoca,
Memorandumului st., no. 28, 400114 Cluj-Napoca, Romania

${ }^{2}$ Centre of Technological Innovation in Static Converters and Drives, Departament of Electrical Engineering, Universitat Politècnica de Catalunya-BarcelonaTech, College of Industrial Engineering of Barcelona, Carrer Comte d'Urgell, 187-08036 Barcelona, Spain

${ }^{3}$ IREC Catalonia Institute for Energy Research, Jardins de les Dones de Negre 1, 08930 Sant Adrià de Besòs, Barcelona, Spain

\author{
abogdan.tomoiaga@enm.utcluj.ro (corresponding author), ${ }^{b}$ mircea.chindris@enm.utcluj.ro, \\ candreas.sumper@upc.edu, ${ }^{\mathrm{d}}$ mmarzband@irec.cat
}

Keywords: microgrids, energy management, distributed generation, energy storage.

\begin{abstract}
The concept of microgrid was first introduced in 2001 as a solution for reliable integration of distributed generation and for harnessing their multiple advantages. Specific control and energy management systems must be designed for the microgrid operation in order to ensure reliable, secure and economical operation; either in grid-connected or stand-alone operating mode. The problem of energy management in microgrids consists of finding the optimal or near optimal unit commitment and dispatch of the available sources and energy storage systems so that certain selected criteria are achieved. In most cases, energy management problem do not satisfy the Bellman's principle of optimality because of the energy storage systems. Consequently, in this paper, an original fast heuristic algorithm for the energy management on stand-alone microgrids, which avoids wastage of the existing renewable potential at each time interval, is presented. A typical test microgrid has been analysed in order to demonstrate the accuracy and the promptness of the proposed algorithm. The obtained cost of energy is low (the quality of the solution is high), the primary adjustment reserve is correspondingly assured by the energy storage system and the execution runtime is very short (a fast algorithm). Furthermore, the proposed algorithm can be used for real-time energy management systems.
\end{abstract}

\section{Introduction}

The concept of microgrid (MG) was first introduced in 2001 as a solution for reliable integration of distributed generation (DG) and for harnessing their multiple advantages [1]. Since then, significant research has been conducted in this area and different model architectures have been proposed in literature. Nowadays there is no unique acceptation of the MG concept but, in essence, a microgrid specifies a small-scale power system (small scale energy zone [2]) which contains DG sources, energy storage (ES) devices, controllable loads (CL), automations, etc. Nowadays, the microgrid concept is quite attractive due to its flexibility, controllability and energy management capabilities. Improvements on power electronics, communication and control systems have allowed developing new technologies for successful integration of renewable energy sources (RES). However, specific control and energy management (EM) systems must be designed for the microgrid operation in order to ensure reliable [3], secure and economical operation (either in gridconnected or stand-alone mode [4]).

In order to ensure long-term stable operation under various load conditions, any microgrid must have a control system (with different time frame adjustments). Typically, three time frame adjustments are used: 
- Primary adjustment (momentary) [5, 6, 7, 8]: Starting from an initial stabilized steady state, any fault occurring in the system (e.g. the loss of the major source, the loss of the major consumer) must not cause transitory decrease of the frequency in such manner to exceed the activation threshold of automatic load-shedding control equipment. The primary adjustment is distributed (decentralised) implemented.

- Secondary adjustment (operation range, several minutes) $[5,6,7,8]$ : For sources which are in operation, the control algorithm varies (changes) the produced active powers. The purpose of secondary adjustment consists of maintaining the desired value of frequency (usually, at the rated/nominal value) and the power balance in order to ensure the primary adjustment reserve. This adjustment can also be used to synchronize the microgrid with the main system facilitating the transition from stand-alone (islanded) to grid-connected mode [5]. The secondary adjustment is centralised implemented (at the entire microgrid level).

- Tertiary adjustment (operation range, 15-30 minutes) [5, 7]: Consists of starting or stopping of some sources, varying the active powers produced by sources which are in operation and varying the active power consumed of loads. The tertiary adjustment is also centralised implemented.

In literature, there is an obvious distinction between primary and secondary adjustment. On the other hand, there is not a unique distinction between secondary and tertiary adjustment. Some authors have considered the secondary adjustment as a mixture between the secondary and the tertiary (the secondary and the tertiary are merged in a single one adjustment strategy) $[6,8]$. The secondary adjustment (or secondary mixed with the tertiary) operates on a slower time frame and must be linked with an EM system (which is responsible for each decision in the microgrid).

The problem of EM in microgrids consists of finding the optimal (or near optimal) unit commitment (UC) [9] and dispatch of the available sources and energy storage (ES) devices so that certain selected criteria (performance indices and objectives [10]) are achieved. This issue was widely investigated in the last decade, and different approaches have been reported in literature. There are authors focused on just achieving some constraints indicating acceptable values for some criteria (e.g. upper and lower limits for sources [11]). Other authors tried to minimize the total power losses for systems with a high dispersion level of DG [12]. Approaches based on aggregation functions have also been reported, taking into account diverse criteria: (i) minimize a cost: sources bids and loads bids [13]; operating and maintenance cost, fuel cost, startup cost, etc. [14] or operating cost, pollutants emissions, the ES systems management [15]; (ii) maximize the profit [16]. Even approaches based on Pareto-optimality have been proposed: minimize end user energy bill and stability of the system [17] or minimize the operating cost and pollutants emissions [18].

Robust approaches, based on the minimization of the microgrid operational cost, by using its local production [19], have been also reported for the EM problem. In other terms, in this case, the most important purpose is to minimize the cost of produced energy [20, 21, 22, 23, 24]. This optimization problem (minimization the cost of produced energy) represents the most important issue. Significant approaches for this purpose have been reported: genetic algorithms [19, 22], generating sets search algorithm [23] and particle swarm optimization algorithm (based on swarm intelligence) [24]. In most cases, EM problem does not satisfy the Bellman's principle of optimality because of the ES systems. On the other hand, the indices which can quantify the quality of an optimization algorithm consist in runtime and the quality of the obtained solution. Consequently, in what follows, a fast heuristic algorithm for the EM problem on stand-alone microgrids will be presented. The proposed EM algorithm has been implemented in a software program and simulation results are also presented.

The paper is organized as follows. Section 2 describes the formulation of the EM problem. A specific aspect regarding the solving of the EM problem, the sorting procedure for power sources, the finding of "pivot source" and the original heuristic algorithm are presented in Section 3. Section 4 presents simulation results which demonstrate the accuracy and the rapidity of the proposed algorithm. Finally, the paper is concluded in Section 5. 


\section{Problem Formulation}

For the EM problem, the input data consist of:

- structure of the microgrid, containing (e.g. Fig 1) [20]:

- different power sources: microturbines (MT), photovoltaics (PV), wind generators (WG);

- loads: uncontrollable (L), controllable/auxiliary (AL);

- ES devices;

- price signals from power sources (a certain price for the generated energy and a certain amount of power for each time interval): these data are given by a day-ahead market [25];

- profiles of uncontrollable loads;

- profiles of renewable sources (PV, WG);

- microgrid operation: stand-alone or grid-connected;

As output data, we will have to find out the optimal operational steady state of the microgrid:

- profiles of non-renewable power sources (MT);

- profiles of auxiliary loads (AL);

- profiles of energy storage (ES) devices;

- the cost of (produced) energy.

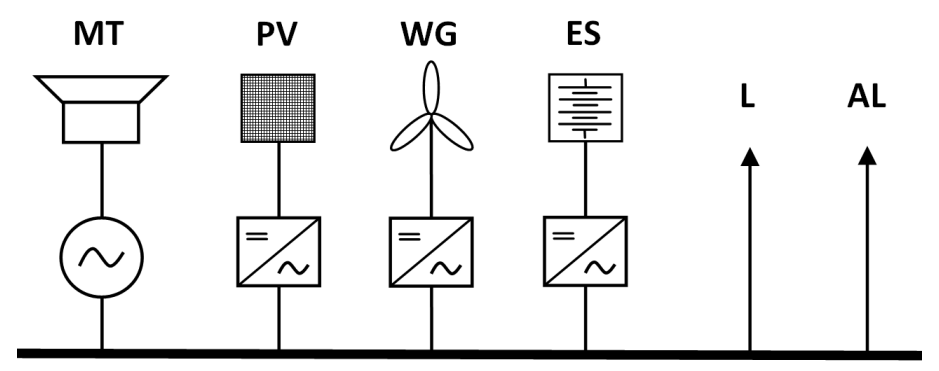

Figure 1: The structure of a test microgrid

As an optimization problem, the proposed form is as follows (in a similar form as in $[19,21,23$, 24]):

- Objective function

$\operatorname{Min}\left[\right.$ CostOfEnergy] $=\operatorname{Min}\left[\sum_{t=1}^{48} \sum_{i=1}^{n} P_{g, i}^{t} \cdot c_{i}^{t} \cdot d\right]$.

- Constraints

- upper and lower limits for sources:

$P_{g, i}^{\min } \leq P_{g, i}^{t} \leq P_{g, i}^{\max }$.

- upper and lower limits for ES as source (minimum and maximum power during discharging mode for ES):

$P_{g E S}^{\min } \leq P_{g E S}^{t} \leq P_{g E S}^{\max }$.

- upper and lower limits for ES as consumer (minimum and maximum power during charging mode for ES):

$P_{c E S}^{\min } \leq P_{c E S}^{t} \leq P_{c E S}^{\max }$.

- energy storage limits (for ES device):

$$
W^{\min } \leq W^{t} \leq W^{\max } .
$$


- power balance:

$$
\sum_{i=1}^{n} P_{g, i}^{t}+P_{g E S}^{t}=\sum_{j=1}^{m} P_{c, j}^{t}+P_{c E S}^{t} .
$$

- upper limits for consumers (L, AL):

$$
P_{c, j}^{t} \leq P_{c, j}^{\max } \text {. }
$$

where: $t$ - time interval; $d$-duration of a time interval $(0.5 \mathrm{~h}) ; n$-total number of sources; $m$-total number of consumers in microgrid; $P_{g, i}$ - active power from source $i(k W) ; P_{g E S}-$ active power from energy storage device $(\mathrm{kW}) ; P_{c, j}$ - active power consumed by consumer $j(\mathrm{~kW}) ; P_{c E S}-$ active power consumed by energy storage device $(k W) ; c_{i}$ - supply bid by source $i(E U R / k W h)$.

\section{Problem Solving}

The EM system has to decide the steady state of each device in the microgrid for each time interval (e.g. $0.5 \mathrm{~h}$ ). Actually, EM system establishes a string of decisions containing the set points for devices, step by step, for each time interval.

It appears that, if at each step (time interval) the optimal solution will be chosen, at the end of the entire process (e.g. one day), the EM will obtain the global optimal solution. Consequently, this optimization problem appears as a dynamic programming one. Unfortunately, the Bellman's principle of optimality ("an optimal policy has the property that whatever the initial state and initial decision are, the remaining decisions must constitute an optimal policy with regard to the state resulting from the first decision." [26]) is not satisfied in this case because of the ES devices: (i) we can have steps where it is important to use an ES device in charging mode, but we cannot because the ES is fully charged (it was fully charged in previous steps); or (ii) we can have steps where it is important to use the battery in discharging mode, but we cannot because the ES is discharged (was fully discharged in previous steps). An illustrative example is given in Fig. 2. Considering step 1 as the initial one (time interval), we can observe that, even if for step 2 the solution given by the Strategy 1 is better than the solution given by Strategy 2, at the end of the process (e.g. after 7 time intervals), the solution given by the Strategy 2 represents the best one (relative to the Strategy 1).

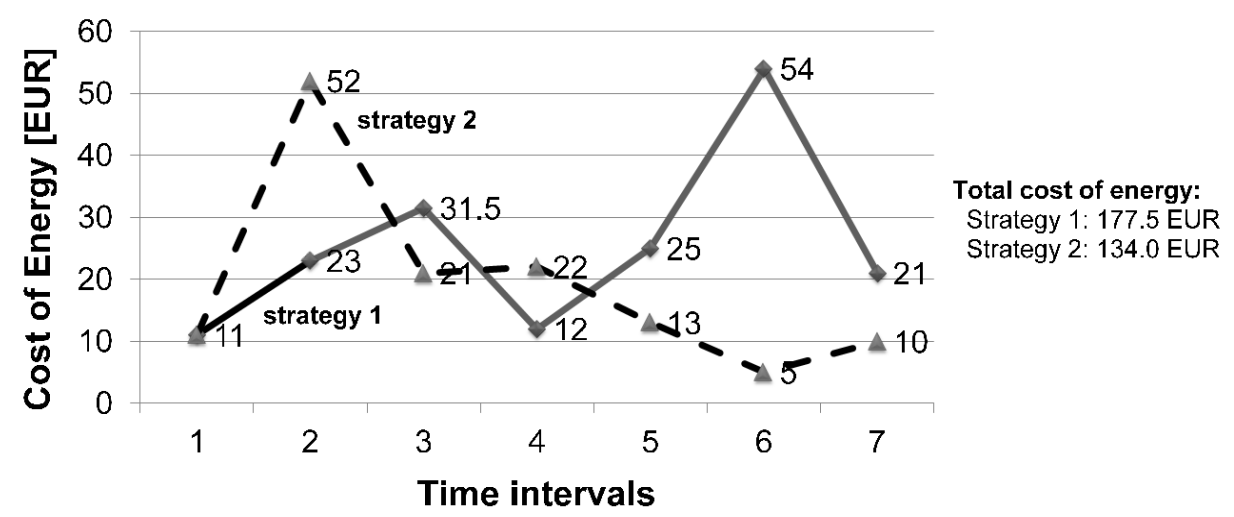

Figure 2: Strategies followed by the EM system

Consequently, in order to solve the EM problem, we propose a heuristic algorithm which is focused on the principle: avoid wastage of the existing renewable potential at each time interval (light, wind, water, etc.).

Sorting Procedure and "Pivot Source". Every generation unit notifies the energy market about its available active power and the price of energy. The sources list (array) is ascendant ordered by the criterion of energy price at each time interval. In our application, taking into account its average complexity, the quick sort algorithm [27] was used. It was developed by Tony Hoare, is based on "divide et impera" (divide and conquer) concept and woks as follows: (i) divide the array on three sub-arrays $A[1 \ldots \mathrm{k}-1], \mathrm{A}[\mathrm{k}], \mathrm{A}[\mathrm{k}+1 \ldots \mathrm{n}]$ (where $\mathrm{A}[\mathrm{k}]>\mathrm{A}[1 \ldots \mathrm{k}-1]$ and $\mathrm{A}[\mathrm{k}]<\mathrm{A}[\mathrm{k}+1 \ldots \mathrm{n}]$ ); (ii) the same idea is recursively applied on arrays $A[1 \ldots \mathrm{k}-1]$ and $A[\mathrm{k}+1 \ldots \mathrm{n}]$. 
Having the ordered list of sources, the crossing point with the horizontal line, indicating the total required power by consumers (loads), represents the market clearing price (MCP) and the "pivot source" (Fig. 3); concomitantly, all offers located under this line are selected as power sources for the microgrid. This decision is valid up to the next time interval, when the presented procedure is once again put into operation.

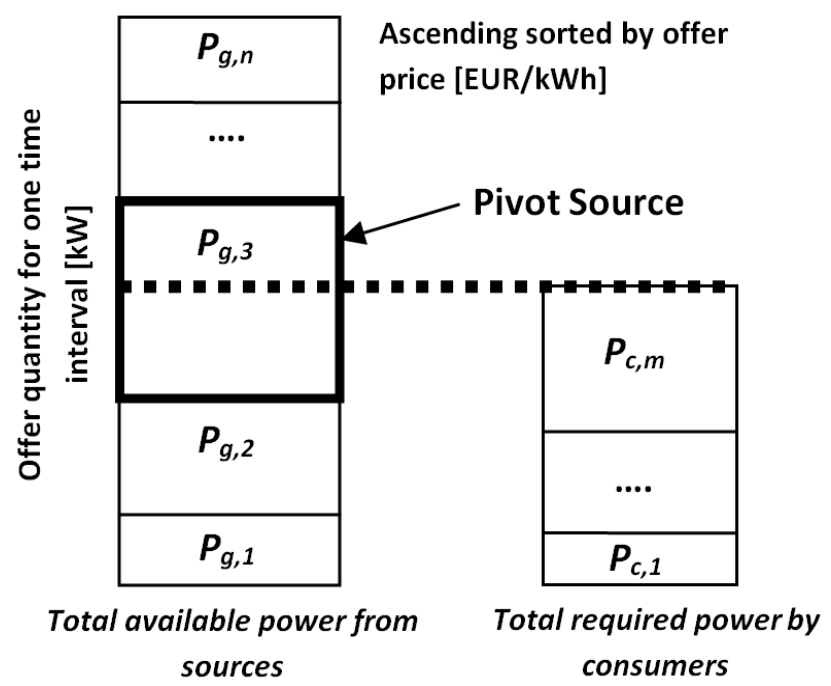

Figure 3: Finding the pivot source at a time interval

Solving Algorithm. In what follows, the proposed algorithm in pseudocode is given:

for TimeInterval $=1$ to 48

\{

a) sort ascendant the sources list by the criterion of energy price (quick sort algorithm)

b) find the PivotSource

c) if PivotSource is renewable: use the entire potential

c1) if $W<0.8 \cdot W^{\max }$ (Eq. 5): charge the ES

c2) if power balance (Eq. 6) is not satisfied:

- start or increase/decrease the consumed power of $A L$

e) if PivotSource is not renewable: try to do not use this source

e1) if $W>0.2 \cdot W^{\min }$ (Eq. 5) and the load demand is covered: discharge the ES

e2) else: use this PivotSource

- if $W<0.8 \cdot W^{\max }($ Eq. 5): charge the ES

- if power balance (Eq. 6) is not satisfied:

- start or increase/decrease the consumed power of $A L$

\}

\section{Simulation Results}

The proposed algorithm has been implemented in the $\mathrm{C}++$ programming language. In order to test the accuracy and the rapidity of this algorithm, the authors have studied the MG from Fig. 1 which contains the following devices: MT, PV, WG, ES, L and AL (e.g. electrical water heater). The test was performed on a PC with Intel Core Duo (3 GHz) processor and with $4 \mathrm{~GB}$ of memory.

As input data, we have: rated parameters for generation units (Table 1), rated parameters for ES system (Table 2), the supply bids by generation units (Table 3), load demand profile (Fig. 4), WG profile (Fig. 5) and PV profile (Fig. 6). The initial state of charge of the ES system $W=2.1[\mathrm{kWh}]$ and the upper power limit for AL is $5 \mathrm{~kW}$. 
Table 1: Rated parameters for each generation unit

\begin{tabular}{|c|c|c|}
\hline $\begin{array}{c}\text { Generation } \\
\text { unit }\end{array}$ & $\begin{array}{c}\text { Minimum instantaneous } \\
\text { power }[\mathbf{k W}]\end{array}$ & $\begin{array}{c}\text { Maximum instantaneous } \\
\text { power }[\mathbf{k W}]\end{array}$ \\
\hline PV & 0 & 8 \\
\hline WG & 0.5 & 9 \\
\hline MT & 3.5 & 15 \\
\hline
\end{tabular}

Table 2: Rated parameters for energy storage system

\begin{tabular}{|c|c|}
\hline Parameter & Value \\
\hline Maximum power during charging mode $[\mathrm{kW}]$ & 0.9 \\
\hline Maximum power during discharging mode $[\mathrm{kW}]$ & 3.5 \\
\hline Maximum stored energy $[\mathrm{kWh}]$ & 2.3 \\
\hline Minimum stored energy $[\mathrm{kWh}]$ & 0.35 \\
\hline Charge efficiency factor $[\%]$ & 97 \\
\hline
\end{tabular}

Table 3: The supply bids by generation units [EUR/kWh]

\begin{tabular}{|c|c|c|}
\hline PV & WG & MT \\
\hline 0.124 & 0.095 & 0.163 \\
\hline
\end{tabular}

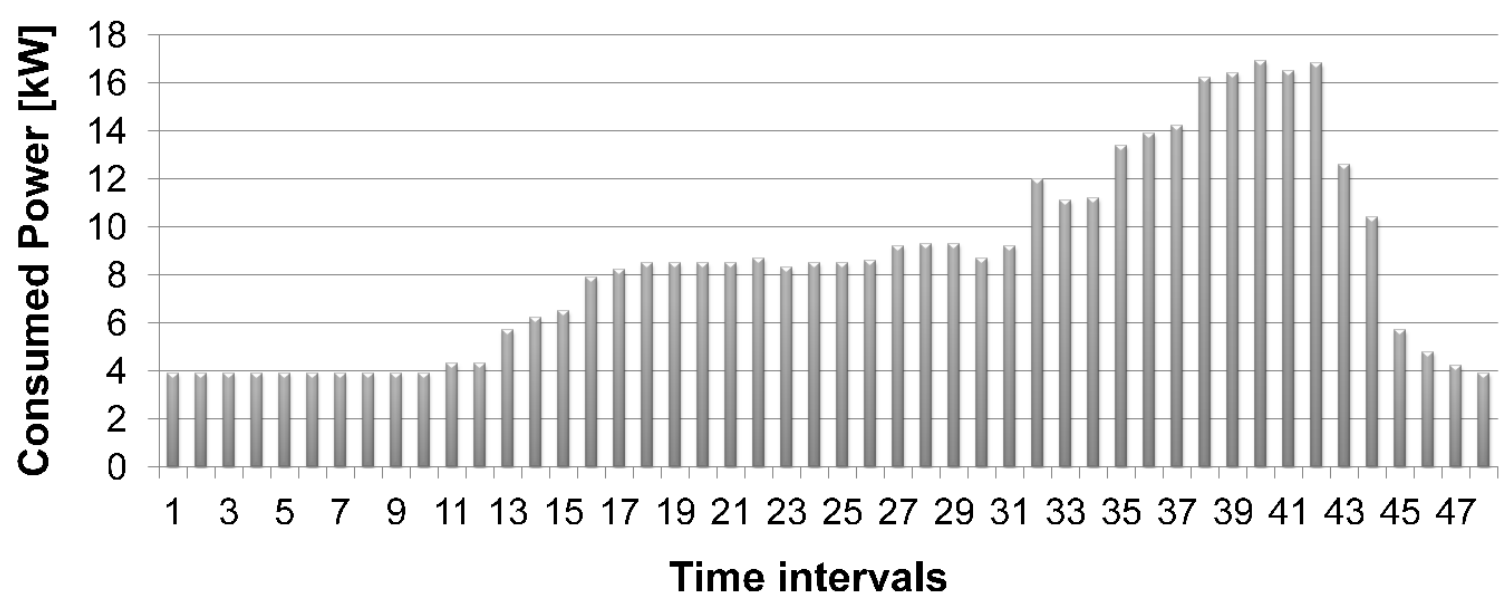

Figure 4: Load demand profile

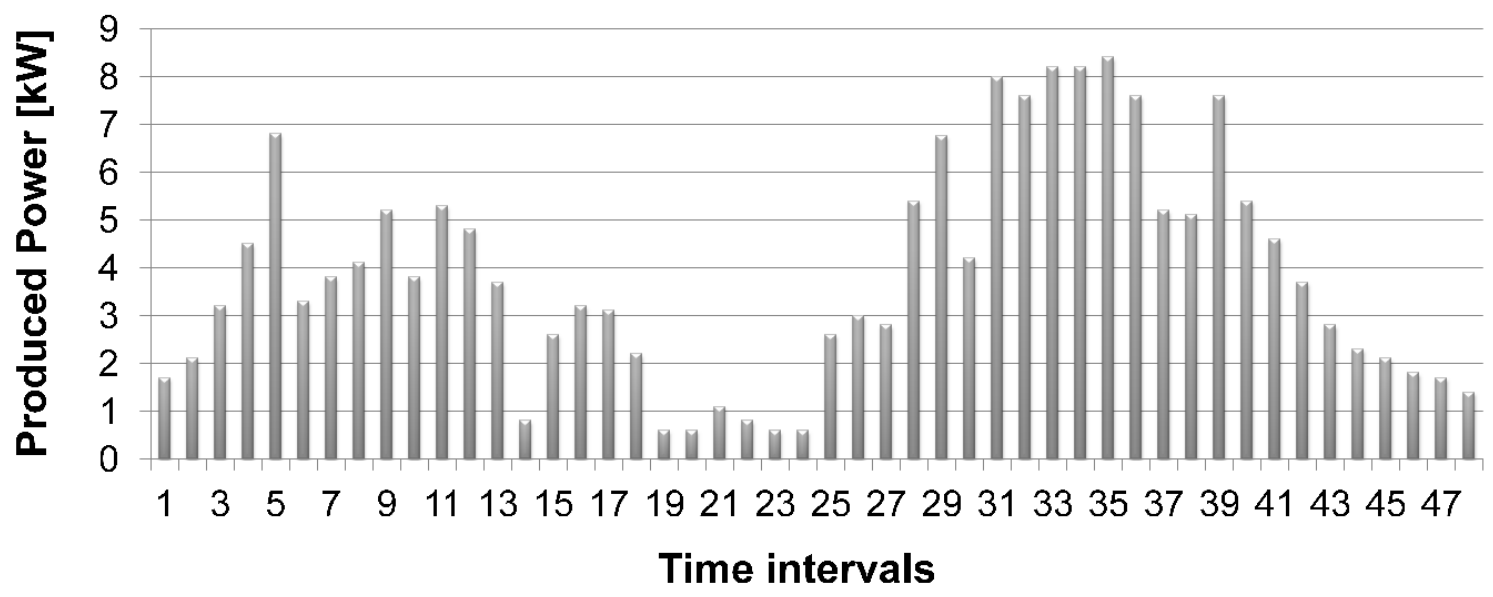

Figure 5: Wind generator profile 


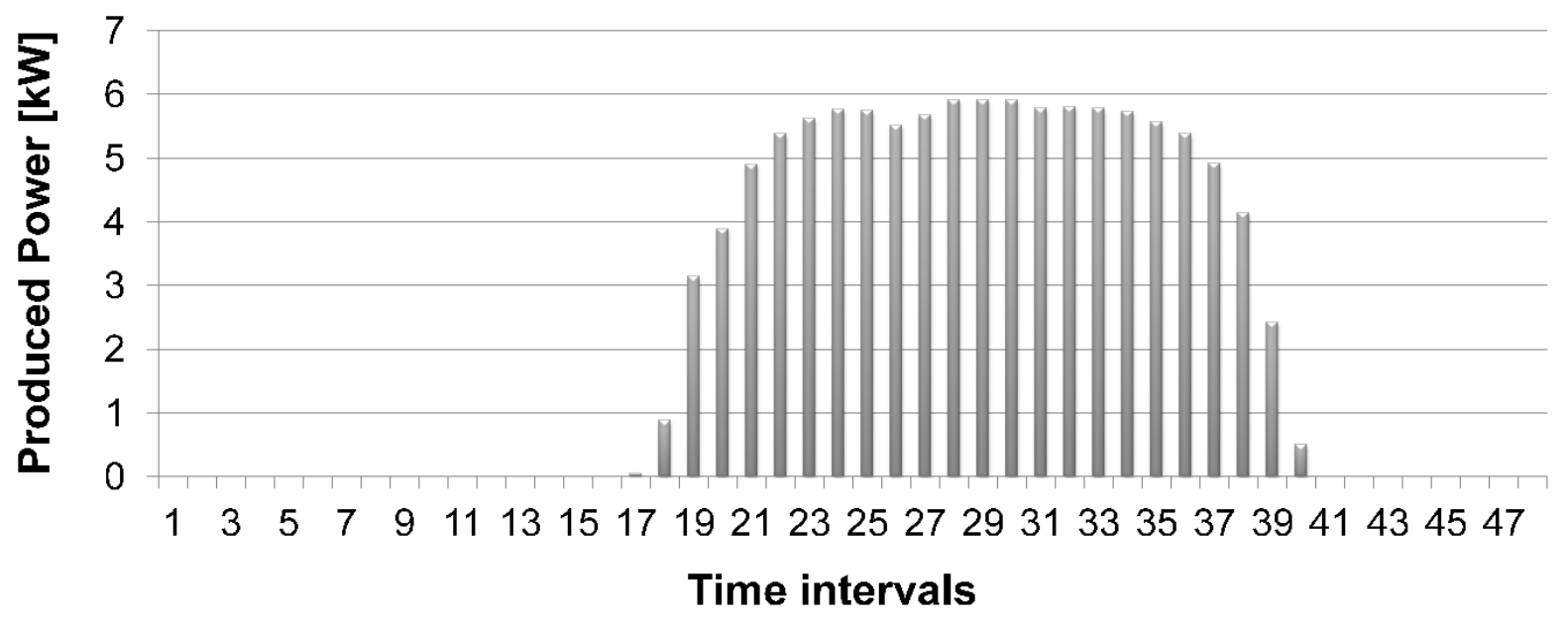

Figure 6: PV profile

As output data, we have obtained: MT profile (Fig. 7), ES profile (Fig.8), state of charge of ES (Fig.9) and AL profile (Fig.10). The total cost of energy (for $24 \mathrm{~h}$ ) is 27.46 EUR (CPU runtime: $160 \mathrm{~ms}$ ). Moreover, the primary adjustment reserve is corresponding assured by the ES system (Fig.9).

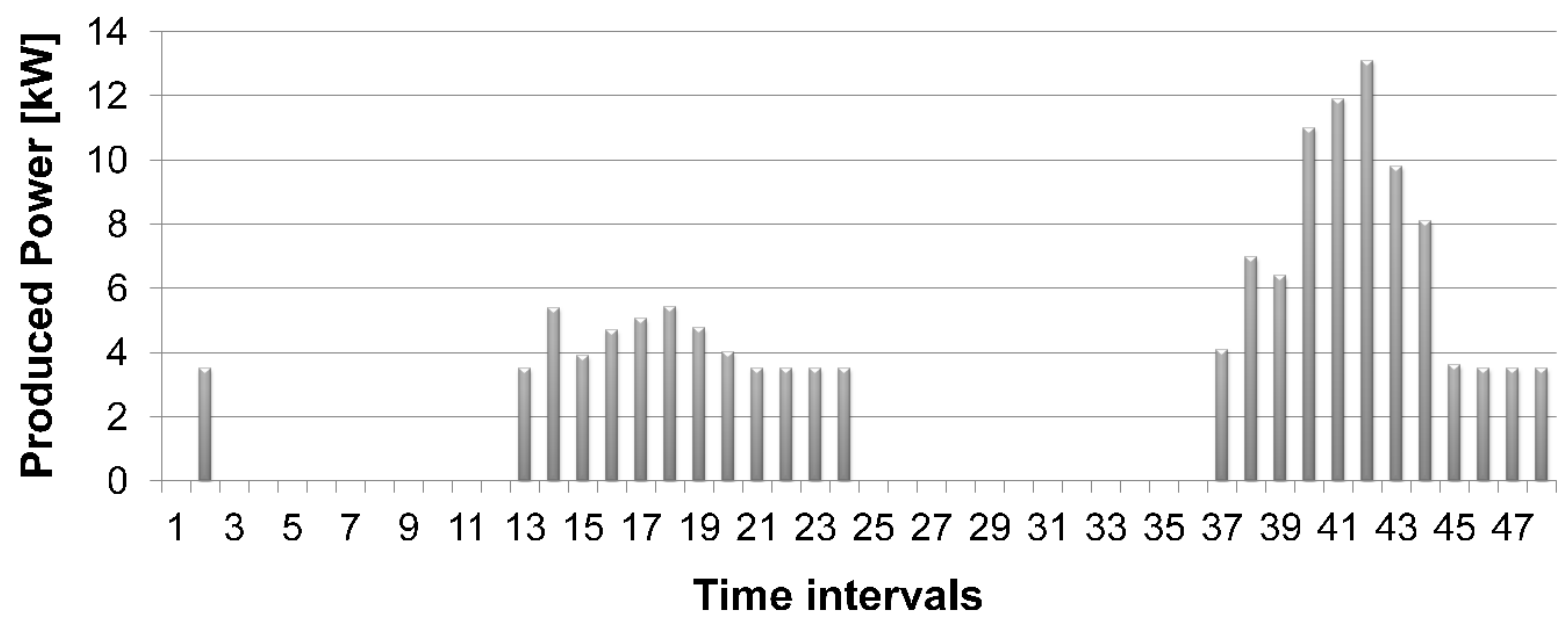

Figure 7: MT profile

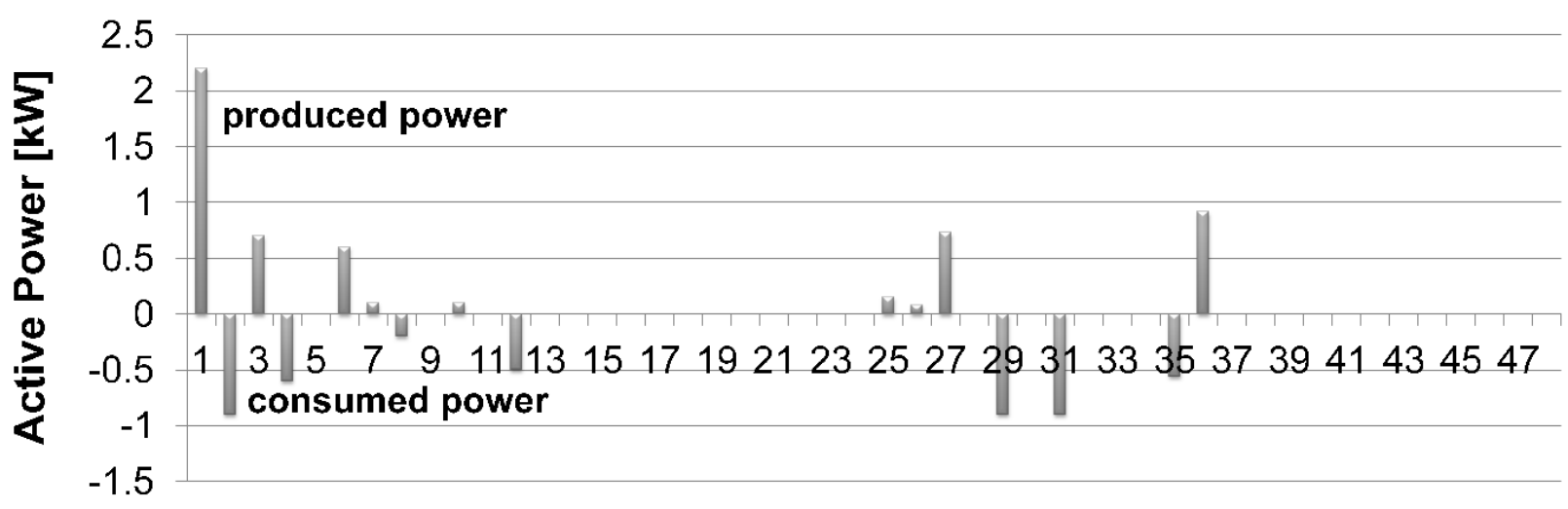

Time intervals

Figure 8: ES profile 


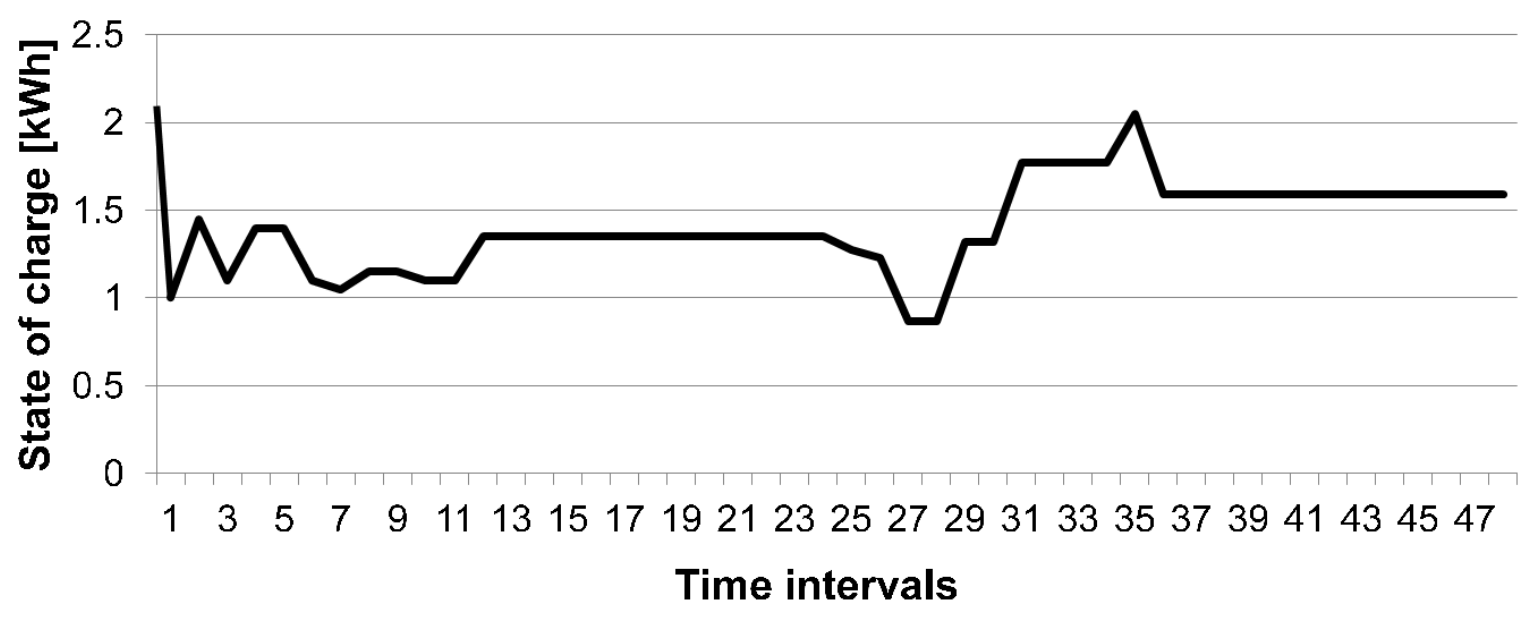

Figure 9: State of charge of ES

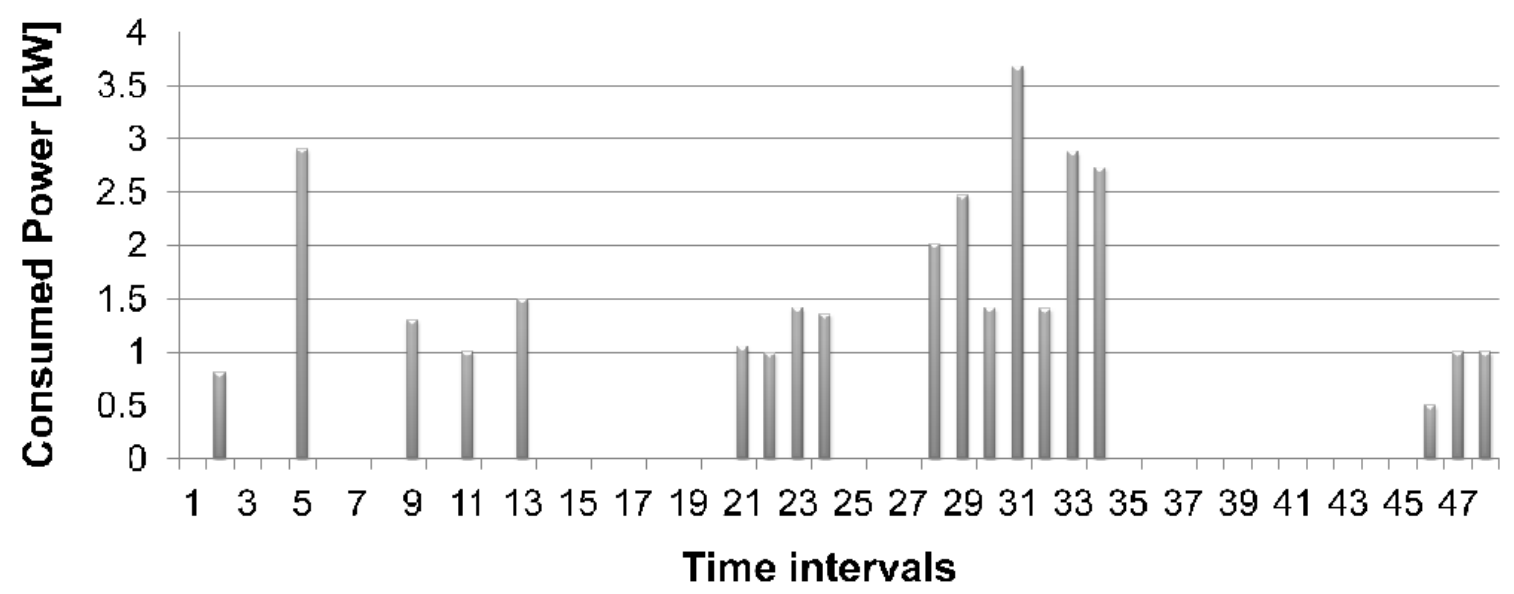

Figure 10: AL profile

By analyzing the obtained data, the following comments and remarks can be made:

- The proposed algorithm does not working with a set of potential solutions as genetic algorithms [19, 22] or particle swarm optimization algorithms [24] do (significant approaches which has been reported in literature for minimization of the cost of produced energy). Due to this facet, the proposed algorithm satisfies an important aim, i.e. to be as simple as possible in order to be a fast one.

- The most important optimization algorithms reported in literature [19, 22, 24] have different behavior at each run; for the same set of input data, at each run, the output data is slightly different because of the stochastic behavior of these approaches. The proposed algorithm, due to its structure, for the same set of input data, always provides the same output data at each run and the algorithm is complex enough in order to obtain a good quality solution.

\section{Conclusion}

In this paper, an original heuristic algorithm is proposed for energy management on microgrids. The energy management problem, as an optimization one, does not satisfy the Bellman's principle of optimality. Consequently, the proposed algorithm is focused on the principle: avoid wastage of the existing renewable potential at each time interval (sunlight, wind, water, etc.). The proposed algorithm has been implemented in the $\mathrm{C}++$ programming language. A typical test microgrid has been analysed which demonstrated the accuracy and the promptness of the proposed algorithm. The obtained cost of energy is low (the quality of the solution is high), the primary adjustment reserve is corresponding assured by the ES system and the execution runtime is very small (a fast algorithm). The proposed algorithm can be used for real-time energy management systems. 


\section{Acknowledgments}

This work was supported by the project "Development and support of multidisciplinary postdoctoral programmes in major technical areas of national strategy of Research - Development Innovation" 4D-POSTDOC, contract no. POSDRU/89/1.5/S/52603, a project co-funded by the European Social Fund through Sectoral Operational Programme Human Resources Development 2007-2013. We would like to thank the IREC (Catalonia Institute for Energy Research) for hosting Bogdan Tomoiagă during his postdoctoral research stage.

\section{References}

[1] B. Lasseter, Microgrids [distributed power generation], Proc. of IEEE-PES Winter Meeting, vol. 1 (Jan./Feb.) (2001) 146-149.

[2] M. Chindris, B. Tomoiaga, P. Taylor, L. Cipcigan, The Load Flow Calculation in Radial Electric Networks with Distributed Generation Under Unbalanced and Harmonic Polluted Regime, Proc. of $42^{\text {nd }}$ International Universities Power Engineering Conference, Brighton, UK (September 4-6) (2007) 947-953.

[3] S. Kennedy, M.M. Marden, Reliability of Islanded Microgrids with Stochastic Generation and Prioritized Load, Proc. of 2009 IEEE Bucharest Power Tech Conference, June $28^{\text {th }}-$ July $2^{\text {nd }}$, Bucharest, Romania (2009) 1-7.

[4] A.H. Kasem Alaboudy, H.H. Zeineldin, J.L. Kirtley, Microgrid Stability Characterization Subsequent to Fault-Triggered Islanding Incidents, IEEE Trans. on Power Delivery 27 (April) (2012) 658-669.

[5] C. Hou, X. Hu, D. Hui, Hierarchical control techniques applied in micro-grid, Proc. of 2010 International Conference on Power System Technology (POWERCON), Beijing, China (October 24-28) (2010) 1-5.

[6] T. L. Vandoorn, B. Zwaenepoel, J. D. M. De Kooning, B. Meersman and L. Vandevelde, Smart microgrids and virtual power plants in a hierarchical control structure, Proc. of 2011 ${ }^{2 n d}$ IEEE PES International Conference and Exhibition on Innovative Smart Grid Technologies (ISGT Europe), Ghent, Belgium (December 5-7) (2011) 1-7.

[7] A. Colet-Subirachs, A. Ruiz-Alvarez, O. Gomis-Bellmunt, F. Alvarez-Cuevas-Figuerola, A. Sudria-Andreu, Centralized and distributed active and reactive power control of a utility connected microgrid using IEC61850, IEEE Systems Journal 6 (2012) 58-67.

[8] T.L. Vandoorn, B. Meersman, J.D.M. De Kooning, L. Vandevelde, Analogy Between Conventional Grid Control and Islanded Microgrid Control Based on a Global DC-Link Voltage Droop, IEEE Transactions on Power Delivery 27 (July) (2012) 1405-1414.

[9] A.D. Hawkes, M.A. Leach, Modelling high level system design and unit commitment for a microgrid, Applied Energy 86 (2009) 1253-1265.

[10] M. Bollen, J. Zhong, Y. Lin, Performance indices and objectives for microgrids, Proc. of $20^{\text {th }}$ International Conference on Electricity Distribution, Prague, (June 8-11) (2009) paper 0607.

[11] H. Kanchev, D. Lu, F. Colas, V. Lazarov, B. Francois, Energy Management and Operational Planning of a Microgrid With a PV-Based Active Generator for Smart Grid Applications, IEEE Trans. on Industrial Electronics 58 (October) (2011) 4583-4592.

[12] F. Katiraei, M.R. Iravani, Power Management Strategies for a Microgrid With Multiple Distributed Generation Units, IEEE Trans. on Power Systems 21 (November) (2006) 18211831.

[13] A.G. Tsikalakis, N.D. Hatziargyriou, Centralized Control for Optimizing Microgrids Operation, IEEE Trans. on Energy Conversion 23 (March) (2008) 241-248.

[14] C. Chen, S. Duan, T. Cai, B. Liu, G. Hu, Optimal Allocation and Economic Analysis of Energy Storage System in Microgrids, IEEE Trans. on Power Electronics 26 (October) (2011) 2762-2773. 
[15] S. Conti, R. Nicolosi, S.A. Rizzo, H.H. Zeineldin, Optimal Dispatching of Distributed Generators and Storage Systems for MV Islanded Microgrids, IEEE Trans. on Power Delivery 27 (July) (2012) 1243-1251.

[16] T Logenthiran, D. Srinivasan, A. M. Khambadkone, H. N. Aung, Multiagent system for realtime operation of a microgrid in real-time digital simulator, IEEE Trans. on Smart Grid 3 (June) (2012) 925-933.

[17] M. Salani, A. Giusti, G.D. Caro, A.E. Rizzoli, L.M. Gambardella, Lexicographic multiobjective optimization for the unit commitment problem and economic dispatch in a microgrid, Proc. of $2^{\text {nd }}$ IEEE PES International Conference and Exhibition on Innovative Smart Grid Technologies (ISGT Europe), Manchester (2011) 1-8.

[18] T. Niknam, R. Azizipanah-Abarghooee, M.R. Narimani, An efficient scenario-based stochastic programming framework for multi-objective optimal micro-grid operation, Applied Energy 99 (2012) 455-470.

[19] C. Chen, S. Duan, T. Cai, B. Liu, G. Hu, Smart energy management system for optimal microgrid economic operation, IET Renewable Power Generation 5 (2011) 258-267.

[20] M. Marzband, A. Sumper, M. Chindris, B. Tomoiaga, Energy management system of hybrid microgrid with energy storage, Proc. of International Word Energy System Conference (WESC), Suceava, Romania (2012).

[21] C. Battistelli, L. Baringob, A.J. Conejo, Optimal energy management of small electric energy systems including V2G facilities and renewable energy sources, Electric Power Systems Research 92 (2012) 50-59.

[22] M. Silva, H. Morais, Z. Vale, An integrated approach for distributed energy resource shortterm scheduling in smart grids considering realistic power system simulation, Energy Conversion and Management 64 (2012) 273-288.

[23] C. Bustos, D. Watts, H. Ren, MicroGrid Operation and Design Optimization with Synthetic Wind and Solar Resources, IEEE Latin America Trans. 10 (March) (2012) 1550-1562.

[24] J. Soares, M. Silva, T. Sousa, Z. Vale, H. Morais, Distributed energy resource short-term scheduling using Signaled Particle Swarm Optimization, Energy 42 (2012) 466-476.

[25] I.C. Paschalidis, B. Li, M.C. Caramanis, Demand-Side Management for Regulation Service Provisioning Through Internal Pricing, IEEE Trans. on Power Systems 27 (August) (2012) 1531-1539.

[26] R.E. Bellman, Dynamic Programming, Princeton University Press, Princeton, NJ, 1957 (Republished 2003).

[27] C.D. Brian, A Simple Expected Running Time Analysis for Randomized 'Divide and Conquer' Algorithms, Discrete Applied Mathematics (2006) 1-5. 